\title{
Comparison of the Complications of Platinum-Based Adjuvant Chemotherapy With and Without Ginger in a Pilot Study on Ovarian Cancer Patients
}

\author{
Farnaz Shokri $^{1}$, Parvin Mostafa Gharebaghi ${ }^{1 *}$, Ali Esfahani ${ }^{1}$, Manizheh Sayyah-Melli ${ }^{1}$, Mehri Jafari Shobeiri ${ }^{1}$, \\ Elaheh Ouladsahebmadarek ${ }^{1}$, Morteza Ghojazadeh ${ }^{1}$
}

\begin{abstract}
Objectives: The principal treatment of ovarian cancer is surgery with or without chemotherapy. The chemotherapy, however, might be ineffective and long with serious side-effects. To obviate these shortcomings, more efficient and safer medications are required, among which ginger has recently gained popularity because of its anti-cancer properties. This study aims to compare outcomes and side-effects of adjuvant chemotherapy with and without ginger in ovarian cancer patients.

Materials and Methods: A total of 49 patients (20 patients in case group and 29 patients in control group) with stage I to III, histopathologically proved ovarian cancer underwent cytoreductive surgery followed by platinum-based adjuvant chemotherapy with and without investigator-prepared oral ginger capsules ( $2 \mathrm{~g}$ per day for 6 cycles). Potential side-effects, poor 12 -month outcome (serum CA125 levels $>35 \mathrm{U}$, radiologic evidence of metastasis and recurrence, or death), and 12-month disease-free survival were documented and compared between the 2 groups.

Results: Poor outcome including serum CA125>35, metastasis, recurrence or death was documented more common in control group (69\% versus 40\%). metastasis frequency confirmed by computerized tomography (CT) scan 6 month after treatment was significantly lower in case group $(P=0.04)$. There was no significant difference regarding mortality and disease free survival during one year follow-up after treatment between 2 groups $(P=0.55)$. Chemotherapy complications such as nausea, vomiting, weight loss, and peripheral neuropathy were detected in case group less than control group but the difference was not significant.

Conclusion: Oral administration of ginger is along with a significantly better 12-month outcome in patients on chemotherapy because of ovarian cancer, and accordingly, considering its safety, its administration is recommended.

Keywords: Ovarian Cancer, Ginger, Chemotherapy, Outcome
\end{abstract}

\section{Introduction}

Of all the female malignancies, most clinical discussions focus on ovarian cancer. It has the highest case fatality ratio and it is the fifth most common cause of malignancyrelated death among women. The cancer is associated with low parity and infertility. Early menarche and late menopause increase the risk of ovarian cancer. Ovarian cancers include epithelial and non-epithelial tumors. More than $80 \%$ of epithelial ovarian cancers are seen in postmenopausal women. The peak incidence of epithelial ovarian cancer is between 55 to 60 years of age. Data show that feature of CA125 increases if the test is performed by transvaginal ultrasound. Its symptoms include complex pelvic mass such as solid pattern, heterogeneous component with irregular thick septum, bilateral masses, and size of lesions exceeding $8 \mathrm{~cm}$. The effective factors in the prognosis of ovarian cancer are divided into the 3 categories of pathological, biological and clinical factors. The pathological factors include the structure and degree of lesion. The biological factors include ploidy and proto-oncogenes such as HER-2neu. The clinical factors include the stage of tumor, the extent of residual disease after primary surgery, volume of ascites, age of the patient, and functional status of patient. Ovarian cancer treatment includes primary cytoreductive and then chemotherapy (1). Chemotherapy may be associated with the complications such as nausea and vomiting, bone marrow depression, peripheral neuropathy, weight loss, hemolytic anemia, and transient cortical blindness (2). Ginger is a plant with anti-carcinogenic and antioxidative effects and modern studies have shown other treatment effects such as the ability to inhibit formation of inflammatory products, direct anti- inflammatory effects, and anti-tumoral effects. It has been proved that the active ingredient in ginger can kill cancer cells due to apoptosis and autophagocytosis. This has also been emphasized in ovarian cancers (2).

On the other hand, although chemotherapy drugs suppress inflammatory markers, cancer cells may show resistance to them. It has been proved that ginger can 
reduce such adverse effects (3). Evaluation of the treatment result for the patients with epithelial ovarian cancer after primary cytoreductive surgery and chemotherapy includes measuring tumor markers (CA125), radiological examination including computerized tomography (CT) scan or abdominal and pelvic Magnetic resonance imaging (MRI), and applying re-evaluation including laparotomy and laparoscopy (1).

The need for further experiences and clinical studies for confirming the effectiveness of ginger in this concern, lack of studies, and high fatality of ovarian cancer in the region made us study the effect of ginger on treating the patients with ovarian cancer compared with the normal treatment without ginger.

\section{Materials and Methods}

This randomized controlled clinical trial examined the effect of ginger on platinum-based adjuvant chemotherapy complications in ovarian cancer patients. The study was conducted in Al-Zahra and Shahid Ghazi health centers in Tabriz. It was performed within 16 months. Initial data collection and data analysis were performed from October 2014 to February 2015. At the beginning of the study, an informed consent was collected in written or verbal forms (for illiterate patients) from any patient. The consents were taken from the patients only and filling out the forms by a spouse or a legal representative was not needed. In addition, an additional cost was not imposed on patients in this project, but it was borne by the executor. The study was approved by the Committee of Ethics of Tabriz University of Medical Sciences.

The inclusion criteria included the females with approved ovarian cancer who underwent primary cytoreductive surgery, willingness to participate in the study. The exclusion criteria included allergy to ginger, history of chemotherapy, history of other malignancy in women, reception of vitamin $\mathrm{E}$ and omega-3 before or concurrent with chemotherapy, chemotherapy intolerance and patients with stage 4 ovarian cancer.

A total of 49 patients with ovarian cancer who underwent primary cytoreductive surgery with approved serous or mucinous ovarian epithelial cancer in their pathologic reports and candidate for chemotherapy entered the study. The patients were divided into 2 random groups. They were then divided into 2 homogeneous groups (using Randlist) based on their satisfaction to receive ginger in terms of the history of lack of neoplastic diseases in women, history of lack of chemotherapy and stage of cancer: (A) Control group including 29 patients who were identified by letter $A$. They received carboplatin at a dose of 5-6 AUC and paclitaxel at a dose of $175 \mathrm{mg} / \mathrm{m}^{2}$ for 6 cycles and 2 capsules of placebo daily along with the treatment; (B) Intervention group including 20 patients who were identified by letter B. They were exposed to the same chemotherapy protocol plus edible ginger (1 g ginger capsule made in Tabriz Faculty of Pharmacy) 2 capsules daily along with the 6 cycles of treatment. Both protocols were repeated every 21 days and it was decided to discontinue the drug and exclude the patients in case of unforeseen complications while taking ginger and/or chemotherapy intolerance. Examiners and the patients were unaware of the coding and the real grouping was only specified after statistical analysis. At the end of the treatment, the tumor marker CA125 of any patient was measured and their abdominal and pelvic CT scans were prepared every 3 months up to 12 months after the baseline (or time of death in relevant cases). An adverse complication was considered as metastasis or malignancy recurrence symptoms in the imaging in every stage and CA125 serum level over 35 units in the final examination/ death. It should be noted that the abdominal and pelvic CT scan was performed by a radiologist and a single laboratory reported the rate of CA125. The laboratory and radiology results were considered as the primary complication. Meanwhile, any lesion was recorded. Finally, the study variables (continuation) between the 2 groups were compared.

\section{Statistical Analysis}

SPSS statistics software version 16.0 was used to analyze the data. Normal distribution of the quantitative data was confirmed by Kolmogorov-Smirnov test. Comparison of the quantitative data for independent groups was made by $t$ test. Comparison of the quantitative data was made using the chi-square test or the Fisher exact test. The KaplanMeier survival curve was drawn during a 12-month follow-up. $P<0.05$ was considered statistically significant.

\section{Results}

Twenty patients in the intervention group and 29 patients in the control group were studied. The average ages of the patients in the intervention and control group were $52.70 \pm 10.55$ years ( 26 to 72 ) and $52.69 \pm 15.56$ years ( 24 to 88 ), respectively. The $t$ test result for independent groups showed no statistically significant difference between the 2 groups regarding age $(P=0.99)$. The average ages of menarche in the intervention and control groups were $11.90 \pm 1.02$ years (10 to 14 ) and $11.90 \pm 1.45$ years (10 to $16)$, respectively. The $t$ test result for independent groups showed no statistically significant difference between the 2 groups regarding the age of menarche $(P=0.99)$. The average ages of menopause in the intervention and control groups were $49.29 \pm 3.67$ years ( 45 to 57 ) and $49.25 \pm 3.51$ years (40 to 53). The educational level of the patients was the same in both groups (Table 1).

The average previous pregnancies in the intervention and control groups were $3.65 \pm 0.63$ ( 0 to 8 ) and $3.86 \pm 0.53$ ( 0 to 10 ), respectively. The $t$ test result for the independent groups showed no statistically significant difference between the 2 groups as far as the average previous pregnancies were concerned $(P=0.80)$. The average parity in the intervention and control groups was $3.20 \pm 0.57$ $(0-8)$ and $3.07 \pm 0.48(0-10)$, respectively. The $t$ test for independent groups showed no statistically significant 
Table 1. Comparison the Educational Level of Case and Control Group

\begin{tabular}{lll}
\hline Level of Education & $\begin{array}{l}\text { Case } \\
\text { No. (\%) }\end{array}$ & $\begin{array}{l}\text { Control } \\
\text { No. (\%) }\end{array}$ \\
\hline Illiterate & $2(10)$ & $2(6.9)$ \\
High school & $1(5)$ & $11(37.9)$ \\
Diplomas & $11(55)$ & $8(27.6)$ \\
University education & $6(30)$ & $8(27.6)$ \\
\hline
\end{tabular}

difference between the 2 groups as far as parity was concerned $(P=0.86)$. The average previous abortions in the intervention and control groups were $0.35 \pm 0.13(0$ 2 ) and $0.76 \pm 0.20(0-5)$, respectively. The $t$ test result for the independent groups showed no statistically significant difference between the 2 groups as far as the average previous abortions were concerned $(P=0.13)$. No history of infertility was observed in the intervention group and one patient $(3.4 \%)$ in the control group was reported to have history of infertility. The Fisher exact test showed no statistically significant difference between the 2 groups as far as the history of infertility was concerned $(P=0.59)$. As far as the history of hormonal drugs consumption was concerned, only 2 patients $(10 \%)$ had the history of OCP consumption. One of the members of control group (3.4\%) had the history of OCP consumption and one member (3.4\%) had the history of infertility treatment. As far as the residence was concerned, 17 patients of the intervention group (85\%) lived in urban areas and 3 $(15 \%)$ lived in rural areas. In the control group, 21 patients (72.4\%) lived in urban areas and 8 patients $(27.6 \%)$ lived in rural areas. The Fisher exact test showed no statistically significant difference between the 2 groups as far as the residence was concerned $(P=0.49)$. As far as the cancer stage in the intervention group was concerned, 5 patients (25\%), 10 patients $(50 \%)$, and 5 patients $(25 \%)$ were in stages I, II, and III, respectively. In the control group, 8 patients $(27.6 \%), 14$ patients $(48.3 \%)$, and 7 patients (24.1\%) were in stages I, II, and III, respectively. The chi-square test result showed no statistically significant difference between the 2 groups as far as the cancer stage was concerned $(P=0.98)$.

\section{Treatment Complications}

Examiners evaluated the patients in the case and control group by history and physical examination during the chemotherapy and detected any complications of treatment. We followed the patients every 3 months by physical exam, serum level of CA125 and CT scan up to12 months.

\section{Nausea and Vomiting}

Eight members of the intervention group and 14 members of the control group had nausea and vomiting. The chisquare test result showed no statistically significant difference between the 2 groups $(P=0.57)$.
Weight Loss

One member of the intervention group and one member of the control group had weight loss. The Fisher exact test showed no statistically significant difference between the 2 groups $(P=0.66)$.

\section{Peripheral Neuropathy}

Three members in the intervention group and 5 members in the control group had peripheral neuropathy. The Fisher exact test showed no statistically significant difference between the 2 groups $(P=0.58)$.

\section{Bone Marrow Depression}

Two patients in the intervention group and 2 members of the control group had bone marrow depression. The Fisher exact test showed no statistically significant difference between the 2 groups $(P=0.54)$.

\section{Transient Cortical Blindness}

One patient in the intervention group and no member of the control group had transient cortical blindness. The Fisher exact test showed no statistically significant difference between the 2 groups $(P=0.41)$.

\section{Any Other Complication}

Ten patients in the intervention group and 21 members of the control group were with some other hematologic, renal and digestive complications. The Fisher exact test showed no statistically significant difference between the 2 groups $(P=0.11)$.

In the intervention group, CA125 means at baseline, 3 months, 6 months, 9 months, and 12 months after treatment were $418.14 \pm 174.18$ units (7-3191), $149.78 \pm 39.45$ units (4-501), $43.60 \pm 127.23$ units (1-612), 20.96 \pm 68.02 units (1-373), and $11.42 \pm 28.66$ units (9-216), respectively. In the control group, CA125 means at baseline, 3 months, 6 months, 9 month and 12 months after treatment were $336.63 \pm 89.82$ units (2-2377), $217.47 \pm 58.32$ units (41222), $134.49 \pm 36.09$ units (2-751), 87.17 \pm 22.65 units (2-498), and 63.39 \pm 21.20 units (4-502), respectively. The results of repeated measurements showed no statistically significant difference between the intervention and control groups as far as the reduction of level of this serum variable during the study intervals was concerned $(P=0.80)$.

The abnormal (increased) CA125 was registered at the end of the follow-up in the intervention group for 5 patients and in the control group for 12 patients. The chisquare test showed no statistically significant difference between the 2 groups $(P=0.24)$.

Table 2 summarizes and compares the results of CT scans in terms of the presence of metastasis at different times in the 2 groups. The chi-square test showed metastasis frequency in the baseline and sixth month CT scans after treatment was significantly higher in the control group. No statistically significant difference was seen in other cases. During a 12-month follow-up period, 
2 and 3 mortalities were seen in the intervention group and the control group, respectively. The Fisher exact test showed no statistically significant difference between the 2 groups $(P=0.68)$. Figure 1 shows the relevant KaplanMeier curves in both groups during a 12-month follow-up period after treatment.

The adverse prognoses for 8 patients in the intervention and 20 patients in the control group were registered. The chi-square test showed that the frequency of adverse prognosis in the control group was significantly higher than the one of the intervention group (odds ratio [OR] $=3.3, P=0.04)$.

The average disease-free survival during a oneyear follow-up after treatment in the intervention and control groups were $11.85 \pm 0.49$ months (10 to 12 ) and $11.72 \pm 0.84$ months (9 to 12 ), respectively. The $t$ test showed no statistically significant difference between the 2 groups $(P=0.55)$.

\section{Discussion}

This clinical trial examined the effect of edible ginger extract on the complications of platinum-based adjuvant chemotherapy in ovarian cancer patients. The research results showed that ginger improved significantly the adverse prognosis of the patients who received ginger as compared with the control group. The impact on chemotherapy complications was favorable, but statistically non-significant. Ginger or Zingiber officinale has been considered effective in preventing a range of chemotherapy-associated complications such as nausea and vomiting (4-7), metabolic disorders (8), and even reproductive system problems (9). It has even been used for appetite stimulation (10) and refreshment in cancer patients (11). In addition, this plant has been used in traditional medicine as an anti-cancer drug for many years and its great effect in modern medicine has been approved (12-16). Finally, its role in exacerbating the effects of chemotherapy is one of the issues of interest in modern medicine (17-20). The benefits of ginger in this field include its nature, strong antioxidant activity, high bioavailability, metabolism simplicity, and low cost as compared with chemotherapy drugs (21).

Studying the available data resources showed that the clinical use of ginger has been mostly for preventing chemotherapy-related complications, especially nausea and vomiting. The role of ginger in this field is not a new case and it has a deep root in traditional medicine. Even today, it is used for making antinausea compounds in the German Pharmacopoeia (22).

The major pharmacological function of ginger in this field is attributed to its active components such as gingerol and shogaol. The components contain antinausea, antipyretic, antitussive, anti-inflammatory, anti-hypertensive and anti-cancer effects. It has also been proved that ginger may reduce the level of prostaglandins and remove digestive problems due to having these types of compounds. Modern studies show that the antiemetic effects of the 2 active ingredients in ginger extract
Table 2. The Results of the CT Scans Performed for the Presence of Metastases at Different Times in the Intervention and Control Groups

\begin{tabular}{lccc}
\hline Different Times & $\begin{array}{c}\text { Intervention }(\mathbf{n}=\mathbf{2 0}) \\
\text { No. (\%) }\end{array}$ & $\begin{array}{c}\text { Control }(\mathbf{n}=\mathbf{2 9}) \\
\text { No. (\%) }\end{array}$ & $\boldsymbol{P}$ value \\
\hline Baseline & $9(45)$ & $21(72.4)$ & $0.05^{*}$ \\
1st quarterly & $8(40)$ & $15(51.7)$ & 0.42 \\
2nd quarterly & $5(25)$ & $16(55.2)$ & $0.04^{*}$ \\
3rd quarterly & $7(35)$ & $13(44.8)$ & 0.49 \\
4th quarterly & $6(33.3)$ & $14(53.8)$ & 0.18 \\
Total & $8(40)$ & $17(58.6)$ & 0.20 \\
\hline
\end{tabular}

$* P \leq$ is significant.

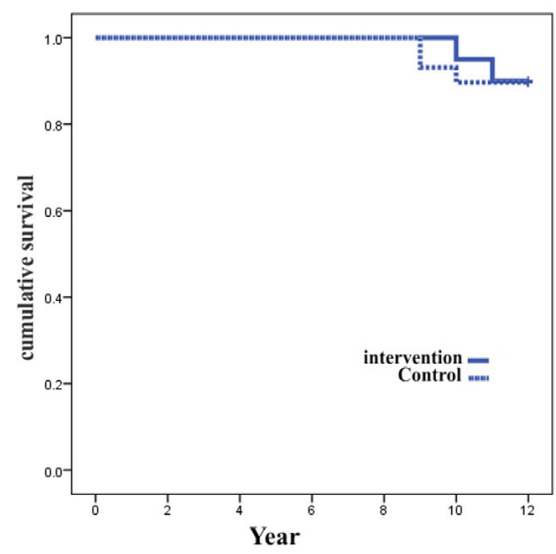

Figure 1. Kaplan-Meier Curves for the 12-Month Mortality in Intervention and Control Groups.

are applied through 2 mechanisms: reducing gastric contractions and increasing the activity of other digestive organs. In addition, the plant has anti-serotonin effects and neutralizes the free radicals leading to nausea $(22,23)$.

Some studies such as the one conducted by Sontakke et al on cancer patients undergoing chemotherapy concluded that ginger administration outperforms the standard antinausea medications such as Metoclopramide (24).

The study of Sripramote and Lekhyananda on 43 cancer patients undergoing chemotherapy proved that ginger administration for this group of patients was effective in reducing late-phase nausea and vomiting (25).

However, the results of different studies in this field have not always had similar outcomes. For example, Eberhart et al concluded that administration of ginger in women who had undergone reproductive system laparoscopy had no effect on the incidence of postoperative nausea and vomiting (26). One of the reasons for such conflicting results is the difference of studies as far as methodology, sample size, and quality of the products containing ginger are concerned. For instance, the study of Nanthakomon and Pongrojpaw concluded that ginger is able to reduce the risk of nausea and vomiting up to $18.4 \%$; however, the difference was not statistically significant due to the low sample size (27).

Other studies proved that ginger administration reduces nausea and vomiting as compared with standard 
antinausea medications in the patients undergoing chemotherapy; however, the difference was not statistically significant due to the low sample size $(28,29)$.

The incidence of nausea and vomiting in the intervention group of our study was lower than the one in the control group ( $40 \%$ versus $48.3 \%$ with the reduction rate of $8.3 \%$ ), but the difference was statistically non-significant. Therefore, further studies with larger sample size are needed in this field to reach firm conclusions. This is also important from another point of view. This is the first study, which examines the frequency of other chemotherapyassociated complications in 2 groups of intervention and control. Based on this, the incidence of the complications in the intervention group was generally lower than the control group (50\% versus $72.4 \%$ ). As mentioned earlier, insufficient sample size hinders us from reaching a definitive conclusion in this regard, as some complications such as reversible blindness and neuropathies, unlike nausea and vomiting, are not so common. In addition to affecting chemotherapy-associated complications, the role of ginger in treating cancer patients and contributing to the effects of chemotherapy is more important, as they can be seen while examining the available data resources of many recent studies in this field. A recent research by Rastogi et al in 2015 examined the effect of administering ginger extract on cervix cancer cells. They concluded that ginger applies such antitumorigenic and proapoptotic effects against a range of cancers, as it contains 6-gingerol or $6 \mathrm{G}$ alkanol-polyphenolic. Mechanism of action of ginger in this field is summarized as follows:

1) Inhibiting the activity of proteasomes chymotrypsin, 2) Reactivating p53 induction, 3) Increasing p21 levels, 4) Damaging DNA and arresting cell cycle of cancer cells in $\mathrm{G} 2 / \mathrm{M}$ phase, 5) Changing levels of apoptotic markers related to p53 such as caspase-3 and PARP, 6) Increasing cytotoxicity of the drugs used in chemotherapy such as cisplatin.

It has been stated that the resultant of all functions enhances death of cancer cells and improves the efficiency of chemotherapy (30).

Other studies emphasized the anti-inflammatory and anti-cancer specifications of 6G. For instance, it has been proved that such an ingredient in ginger extract may inhibit iNOS and IkBa while releasing cytochrome c, activate caspase, increase Apaf-1 expression, induct oxidative stress, damage DNA, stimulate autophagy, and activate tumor-suppressor proteins in the cancer cells. The resultant of all these factors ends in inducting and increasing apoptosis (21,31-37).

In 2015, Wee et al proved that ginger extract might be used in treating colon cancer. This study, which was conducted at a cellular level, reports the anticancer mechanism of ginger in inhibiting mTOR and inducting apoptosis pathways (38).

The anti-cancer effect of ginger on patients with colon cancer and other gastrointestinal cancers was emphasized in other studies (39-42).

In 2015, Ray et al showed that ginger extract is able to inhibit and destroy breast cancer cells. The proposed mechanism in this study is apoptosis induction by ginger (43).

In 2014, Sehrawat et al reported that ginger extract is useful for removing breast cancer cells. Such a beneficial effect has been applied through activating Notch2, which leads to inactivation of proapotic and migration responses of cancer cells (44).

In a study by Chan et al, ginger extract could destroy prostate cancer cells at the cellular level. Such an anticancer effect was achieved through binding to tubulin and establishing a connection between endoplasmic reticulum stress and mitochondrial damage (45). A similar result was reported by Saha et al (46).

Akimoto et al proved that ginger extract at the cellular level can be useful through inducting apoptosis by increasing ROS activity in pancreatic cancer treatment (47). Hsu et alemphasized the anticancer effects of ginger at the cellular level on lung cancer (48). In a similar cellular study, Han et aldiscussed and reported the useful effects of ginger extract for kidney cancer (49).

In 2014, Parvizzadeh et al proved that ginger could improve the chemotherapy effect of cancers. This study reported the favorable effects of ginger extract in this concern through changes in the metabolic pathways of cancer cells in terms of protein and amino acid biosynthesis and metabolism of carbohydrates to enhance the cytotoxic effects of chemotherapy (50).

In 2015, Fan et al highlighted the anticancer effect of ginger extract on osteosarcoma in a cellular study (51).

In 2014, Poltronieri et al emphasized the role of ginger extract in preventing and inhibiting cancer metastasis (52).

As it is noticed, the use of ginger in treating or helping to treat a range of cancers has been emphasized. What is of paramount importance in this concern, as stated earlier, is that all the studies are new, which emphasizes its importance and interest of modern medicine in using such a traditional herbal substance. However, studying the available data resources revealed that only 2 studies have discussed this matter on ovarian cancer. Rhode et al discussed the effect of ginger extract on ovarian cancer cell lines at a laboratory level. The study findings showed that ginger inhibited cancer cells strongly. These effects were applied through inhibiting NF-kB activation and reducing VEGF and IL-8 secretion, which play a major role in angiogenesis of cancer cells (3). Pashaei-Asl et al studied the inhibitory effect of ginger extract on ovarian cancer cell line. They found that the ginger extract has anticancer properties inducing apoptosis through p53 pathway and p53 expression is the main reason for the cytotoxicity effects of ginger in ovarian cancer cells and the cause of cell death in SKOV-3 cells (53). Based on these, the study proposed clinical trials in this field $(3,53)$.

Although the available data on carcinogenesis and its definitive mechanisms on ovarian cancer are limited, it seems that the major components in this regard include inflammation and cancer cells coping strategies. Lack of 
response to growth inhibitory signals, evasion of apoptosis, unlimited capacity to proliferate, and continuous angiogenesis were observed among the cases considered in this concern. All these mechanisms have been strongly controlled by NF- $\kappa \mathrm{B}$ gene, which is continuously active in most cancers, including ovarian cancers. Therefore, it seems that focusing on this factor plays a major role in controlling and inhibiting ovarian cancer (54).

Ironically, unrelated studies have shown that ginger extract had a major impact on controlling the pathway related to NF- $\mathrm{KB}$ and inhibiting cancer-associated angiogenesis. Such a specific impact is apart from other favorable effects of ginger as an anticancer substance such as antioxidant, anti-inflammatory, and anti-carcinogenesis functions $(31,55-73)$.

The present study is of paramount importance, as it is the first randomized clinical trial on examining the effect of ginger on the chemotherapy complications of ovarian cancer and it proved the useful effects of ginger in a clinical manner in reducing unfavorable complications. Although further studies are required using a larger sample size and a longer follow-up period to reach definitive results, it can be administered for these types of cancer patients, as the substance was not associated with a major complication in this study.

\section{Ethical Issues}

This study was registered under code No. IRCT2014031510901N4 on the website of Iranian Registry of Clinical Trials (http://irct.ir).

\section{Conflict of Interests}

The authors declare no conflict of interests.

\section{Financial Support}

Women's Reproductive Health Research Center, Tabriz University of Medical sciences supported this study.

\section{Acknowledgements}

We would like to thank authorities of Tabriz University of Medical Sciences for the scientific and ethical approval and financial support of this research. This study has been done as a thesis for specialist degree of Farnaz Shokry in Women's Reproductive Health Research Center, Tabriz University of Medical Sciences.

\section{References}

1. Berek JS, Novak E. Berek \& Novak’s Gynecology. Lippincott Williams \& Wilkins; 2007.

2. Ellenhorn MJ. Ellenhorn's Medical Toxicology: Diagnosis and Treatment of Human Poisoning. Lippincot Williams \& Wilkins; 1997.

3. Rhode J, Fogoros S, Zick S, et al. Ginger inhibits cell growth and modulates angiogenic factors in ovarian cancer cells. BMC Complement Altern Med. 2007;7:44. doi:10.1186/1472-6882-7-44

4. Arslan M, Ozdemir L. Oral intake of ginger for chemotherapy-induced nausea and vomiting among women with breast cancer. Clin J Oncol Nurs. 2015;19(5):E92-97. doi:10.1188/15.cjon.e92-e97

5. Lua PL, Salihah N, Mazlan N. Effects of inhaled ginger aromatherapy on chemotherapy-induced nausea and vomiting and health-related quality of life in women with breast cancer. Complement Ther Med. 2015;23(3):396-404. doi:10.1016/j.ctim.2015.03.009

6. Marx W, Ried K, McCarthy AL, et al. Ginger-Mechanism of action in chemotherapy-induced nausea and vomiting: A review. Crit Rev Food Sci Nutr. 2017;57(1):141-146. doi:10. 1080/10408398.2013.865590

7. Marx W, McCarthy AL, Ried K, et al. Can ginger ameliorate chemotherapy-induced nausea? Protocol of a randomized double blind, placebo-controlled trial. BMC Complement Altern Med. 2014;14:134. doi:10.1186/1472-6882-14-134

8. Shidfar F, Rajab A, Rahideh T, Khandouzi N, Hosseini $\mathrm{S}$, Shidfar S. The effect of ginger (Zingiber officinale) on glycemic markers in patients with type 2 diabetes. J Complement Integr Med. 2015;12(2):165-170. doi:10.1515/ jcim-2014-0021

9. Aghaie S, Nikzad H, Mahabadi JA, et al. Protective effect of combined pumpkin seed and ginger extracts on sperm characteristics, biochemical parameters and epididymal histology in adult male rats treated with cyclophosphamide. Anat Sci Int. 2016;91(4):382-390. doi:10.1007/s12565-0150314-x

10. Sanatani M, Younus J, Stitt L, Malik N. Tolerability of the combination of ginger (Zingiber officinalis), gentian (Gentiana lutea) and turmeric (Curcuma longa) in patients with cancer-associated anorexia. J Complement Integr Med. 2015;12(1):57-60. doi:10.1515/jcim-2013-0064

11. Lee S, Jerng UM, Liu Y, Kang JW, Nam D, Lee JD. The effectiveness and safety of moxibustion for treating cancerrelated fatigue: a systematic review and meta-analyses. Support Care Cancer. 2014;22(5):1429-1440. doi:10.1007/ s00520-014-2161-Z

12. Wang CZ, Qi LW, Yuan CS. Cancer Chemoprevention Effects of Ginger and its Active Constituents: Potential for New Drug Discovery. Am J Chin Med. 2015;43(7):13511363. doi:10.1142/s0192415x15500767

13. Semwal RB, Semwal DK, Combrinck S, Viljoen AM. Gingerols and shogaols: Important nutraceutical principles from ginger. Phytochemistry. 2015;117:554-568. doi:10.1016/j.phytochem.2015.07.012

14. Marrelli M, Menichini F, Conforti F. A comparative study of Zingiber officinale Roscoe pulp and peel: phytochemical composition and evaluation of antitumour activity. Nat Prod Res. 2015;29(21):2045-2049. doi:10.1080/14786419.2 015.1020491

15. Khuda-Bukhsh AR, Das S, Saha SK. Molecular approaches toward targeted cancer prevention with some food plants and their products: inflammatory and other signal pathways. Nutr Cancer. 2014;66(2):194-205. doi:10.1080/0 1635581.2014.864420

16. Shukla Y, Singh M. Cancer preventive properties of ginger: a brief review. Food Chem Toxicol. 2007;45(5):683-690. doi:10.1016/j.fct.2006.11.002

17. Hakim L, Alias E, Makpol S, Ngah WZ, Morad NA, Yusof YA. Gelam honey and ginger potentiate the anti cancer effect of 5-FU against HCT 116 colorectal cancer cells. Asian Pac J Cancer Prev. 2014;15(11):4651-4657.

18. Kim SM, Kim C, Bae H, et al. 6-Shogaol exerts antiproliferative and pro-apoptotic effects through the 
modulation of STAT3 and MAPKs signaling pathways. Mol Carcinog. 2015;54(10):1132-1146. doi:10.1002/mc.22184

19. Fu J, Chen H, Soroka DN, Warin RF, Sang S. Cysteineconjugated metabolites of ginger components, shogaols, induce apoptosis through oxidative stress-mediated p53 pathway in human colon cancer cells. J Agric Food Chem. 2014;62(20):4632-4642. doi:10.1021/jf501351r

20. Baliga MS, Haniadka R, Pereira MM, et al. Update on the chemopreventive effects of ginger and its phytochemicals. Crit Rev Food Sci Nutr. 2011;51(6):499523. doi:10.1080/10408391003698669

21. Oyagbemi AA, Saba AB, Azeez OI. Molecular targets of [6]-gingerol: Its potential roles in cancer chemoprevention. Biofactors. 2010;36(3):169-178. doi:10.1002/biof.78

22. Sheikhi MA, Ebadi A, Talaeizadeh A, Rahmani $\mathrm{H}$. Alternative methods to treat nausea and vomiting from cancer chemotherapy. Chemother Res Pract. 2015;2015:818759. doi:10.1155/2015/818759

23. Manusirivithaya S, Sripramote M, Tangjitgamol S, et al. Antiemetic effect of ginger in gynecologic oncology patients receiving cisplatin. Int J Gynecol Cancer. 2004;14(6):10631069. doi:10.1111/j.1048-891X.2004.14603.x

24. Sontakke S, Thawani V, Naik MS. Ginger as an antiemetic in nausea and vomiting induced by chemotherapy: a randomized, cross-over, double blind study. Indian J Pharmacol. 2003; 35: 32-36.

25. Sripramote M, Lekhyananda N. A randomized comparison of ginger and vitamin B6 in the treatment of nausea and vomiting of pregnancy. J Med Assoc Thai. 2003;86(9):846853.

26. Eberhart LH, Mayer R, Betz O, et al. Ginger does not prevent postoperative nausea and vomiting after laparoscopic surgery. Anesth Analg. 2003;96(4):995-998, table of contents.

27. Nanthakomon T, Pongrojpaw D. The efficacy of ginger in prevention of postoperative nausea and vomiting after major gynecologic surgery. J Med Assoc Thai. 2006;89 Suppl 4:S130-136.

28. Ozgoli G, Goli M, Simbar M. Effects of ginger capsules on pregnancy, nausea, and vomiting. J Altern Complement Med. 2009;15(3):243-246. doi:10.1089/acm.2008.0406

29. Levine ME, Gillis MG, Koch SY, Voss AC, Stern RM, Koch KL. Protein and ginger for the treatment of chemotherapyinduced delayed nausea. J Altern Complement Med. 2008;14(5):545-551. doi:10.1089/acm.2007.0817

30. Rastogi N, Duggal S, Singh SK, et al. Proteasome inhibition mediates p53 reactivation and anti-cancer activity of 6-gingerol in cervical cancer cells. Oncotarget. 2015;6(41):43310-43325. doi:10.18632/oncotarget.6383

31. Kim EC, Min JK, Kim TY, et al. [6]-Gingerol, a pungent ingredient of ginger, inhibits angiogenesis in vitro and in vivo. Biochem Biophys Res Commun. 2005;335(2):300308. doi:10.1016/j.bbrc.2005.07.076

32. Lin CB, Lin CC, Tsay GJ. 6-Gingerol Inhibits Growth of Colon Cancer Cell LoVo via Induction of G2/M Arrest. Evid Based Complement Alternat Med. 2012;2012:326096. doi:10.1155/2012/326096

33. Park YJ, Wen J, Bang S, Park SW, Song SY. [6]-Gingerol induces cell cycle arrest and cell death of mutant p53expressing pancreatic cancer cells. Yonsei Med J. 2006;47(5):688-697. doi:10.3349/ymj.2006.47.5.688

34. Chakraborty D, Bishayee K, Ghosh S, Biswas R, Mandal SK, Khuda-Bukhsh AR. [6]-Gingerol induces caspase 3 dependent apoptosis and autophagy in cancer cells: drugDNA interaction and expression of certain signal genes in HeLa cells. Eur J Pharmacol. 2012;694(1-3):20-29. doi:10.1016/j.ejphar.2012.08.001

35. Liu Y, Whelan RJ, Pattnaik BR, et al. Terpenoids from Zingiber officinale (Ginger) induce apoptosis in endometrial cancer cells through the activation of p53. PLoS One. 2012;7(12):e53178. doi:10.1371/journal.pone.0053178

36. Lee SH, Cekanova M, Baek SJ. Multiple mechanisms are involved in 6-gingerol-induced cell growth arrest and apoptosis in human colorectal cancer cells. Mol Carcinog. 2008;47(3):197-208. doi:10.1002/mc.20374

37. Rastogi N, Gara RK, Trivedi R, et al. (6)-Gingerolinduced myeloid leukemia cell death is initiated by reactive oxygen species and activation of miR-27b expression. Free Radic Biol Med. 2014;68:288-301. doi:10.1016/j. freeradbiomed.2013.12.016

38. Wee LH, Morad NA, Aan GJ, Makpol S, Wan Ngah WZ, Mohd Yusof YA. Mechanism of chemoprevention against colon cancer cells using combined gelam honey and ginger extract via mTOR and Wnt/beta-catenin pathways. Asian Pac J Cancer Prev. 2015;16(15):6549-6556.

39. Qi LW, Zhang Z, Zhang CF, et al. Anti-colon cancer effects of 6-shogaol through G2/M cell cycle arrest by p53/p21cdc2/cdc25A crosstalk. Am J Chin Med. 2015;43(4):743756. doi:10.1142/s0192415x15500469

40. Hwang JS, Lee HC, Oh SC, Lee DH, Kwon KH. Shogaol overcomes TRAIL resistance in colon cancer cells via inhibiting of survivin. Tumour Biol. 2015;36(11):88198829. doi:10.1007/s13277-015-3629-2

41. Tahir AA, Sani NF, Murad NA, Makpol S, Ngah WZ, Yusof YA. Combined ginger extract \& Gelam honey modulate Ras/ERK and PI3K/AKT pathway genes in colon cancer HT29 cells. Nutr J. 2015;14:31. doi:10.1186/s12937-0150015-2

42. Prasad S, Tyagi AK. Ginger and its constituents: role in prevention and treatment of gastrointestinal cancer. Gastroenterol Res Pract. 2015;2015:142979. doi:10.1155/2015/142979

43. Ray A, Vasudevan S, Sengupta S. 6-Shogaol inhibits breast cancer cells and stem cell-like spheroids by modulation of notch signaling pathway and induction of autophagic cell death. PLoS One. 2015;10(9):e0137614. doi:10.1371/ journal.pone.0137614

44. Sehrawat A, Sakao K, Singh SV. Notch2 activation is protective against anticancer effects of zerumbone in human breast cancer cells. Breast Cancer Res Treat. 2014;146(3):543-555. doi:10.1007/s10549-014-3059-7

45. Chan ML, Liang JW, Hsu LC, Chang WL, Lee SS, Guh JH. Zerumbone, a ginger sesquiterpene, induces apoptosis and autophagy in human hormone-refractory prostate cancers through tubulin binding and crosstalk between endoplasmic reticulum stress and mitochondrial insult. Naunyn Schmiedebergs Arch Pharmacol. 2015;388(11):1223-1236. doi:10.1007/s00210-015-1152-Z

46. Saha A, Blando J, Silver E, Beltran L, Sessler J, DiGiovanni J. 6-Shogaol from dried ginger inhibits growth of prostate cancer cells both in vitro and in vivo through inhibition of STAT3 and NF-kappaB signaling. Cancer Prev Res (Phila). 2014;7(6):627-638. doi:10.1158/1940-6207.capr-13-0420

47. Akimoto M, Iizuka M, Kanematsu R, Yoshida M, Takenaga $\mathrm{K}$. Anticancer effect of ginger extract against pancreatic cancer cells mainly through reactive oxygen species- 
mediated autotic cell death. PLoS One. 2015;10(5):e0126605. doi:10.1371/journal.pone.0126605

48. Hsu YL, Hung JY, Tsai YM, et al. 6-shogaol, an active constituent of dietary ginger, impairs cancer development and lung metastasis by inhibiting the secretion of CC-chemokine ligand 2 (CCL2) in tumor-associated dendritic cells. J Agric Food Chem. 2015;63(6):1730-1738. doi:10.1021/jf504934m

49. Han MA, Woo SM, Min KJ, et al. 6-Shogaol enhances renal carcinoma Caki cells to TRAIL-induced apoptosis through reactive oxygen species-mediated cytochrome c release and down-regulation of c-FLIP(L) expression. Chem Biol Interact. 2015;228:69-78. doi:10.1016/j.cbi.2015.01.020

50. Parvizzadeh N, Sadeghi S, Irani S, et al. A metabonomic study of the effect of methanol extract of ginger on Raji cells using (1)HNMR spectroscopy. Biotechnol Res Int. 2014;2014:572534. doi:10.1155/2014/572534

51. Fan J, Yang X, Bi Z. 6-Gingerol inhibits osteosarcoma cell proliferation through apoptosis and AMPK activation. Tumour Biol. 2015;36(2):1135-1141. doi:10.1007/s13277014-2723-1

52. Poltronieri J, Becceneri AB, Fuzer AM, et al. [6]-gingerol as a cancer chemopreventive agent: a review of its activity on different steps of the metastatic process. Mini Rev Med Chem. 2014;14(4):313-321.

53. Pashaei-Asl R, Pashaei-Asl F, Gharabaghi PM, et al. The inhibitory effect of ginger extract on Ovarian cancer cell line; Application of systems biology. Adv Pharm Bull 2017;7:241-249. doi: 10.15171/apb.2017.029.

54. Pacifico F, Leonardi A. NF-kappaB in solid tumors. Biochem Pharmacol. 2006;72(9):1142-1152. doi:10.1016/j. bcp.2006.07.032

55. Kuo JM, Yeh DB, Pan BS. Rapid photometric assay evaluating antioxidative activity in edible plant material. J Agric Food Chem. 1999;47(8):3206-3209.

56. Reddy AC, Lokesh BR. Studies on spice principles as antioxidants in the inhibition of lipid peroxidation of rat liver microsomes. Mol Cell Biochem. 1992;111(1-2):117124.

57. Krishnakantha TP, Lokesh BR. Scavenging of superoxide anions by spice principles. Indian J Biochem Biophys. 1993;30(2):133-134.

58. Ahmed RS, Seth V, Banerjee BD. Influence of dietary ginger (Zingiber officinales Rosc) on antioxidant defense system in rat: comparison with ascorbic acid. Indian J Exp Biol. 2000;38(6):604-606.

59. Banerjee S, Bueso-Ramos C, Aggarwal BB. Suppression of 7,12-dimethylbenz(a)anthracene-induced mammary carcinogenesis in rats by resveratrol: role of nuclear factorkappaB, cyclooxygenase 2, and matrix metalloprotease 9. Cancer Res. 2002;62(17):4945-4954.

60. Sekiwa Y, Kubota K, Kobayashi A. Isolation of novel glucosides related to gingerdiol from ginger and their antioxidative activities. J Agric Food Chem. 2000;48(2):373377.

61. Grzanna R, Lindmark L, Frondoza CG. Ginger--an herbal medicinal product with broad anti-inflammatory actions. J
Med Food. 2005;8(2):125-132. doi:10.1089/jmf.2005.8.125

62. Lantz RC, Chen GJ, Sarihan M, Solyom AM, Jolad SD, Timmermann BN. The effect of extracts from ginger rhizome on inflammatory mediator production. Phytomedicine. 2007;14(2-3):123-128. doi:10.1016/j. phymed.2006.03.003

63. Jolad SD, Lantz RC, Chen GJ, Bates RB, Timmermann BN. Commercially processed dry ginger (Zingiber officinale): composition and effects on LPS-stimulated PGE2 production. Phytochemistry. 2005;66(13):1614-1635. doi:10.1016/j.phytochem.2005.05.007

64. Jolad SD, Lantz RC, Solyom AM, Chen GJ, Bates RB, Timmermann BN. Fresh organically grown ginger (Zingiber officinale): composition and effects on LPS-induced PGE2 production. Phytochemistry. 2004;65(13):1937-1954. doi:10.1016/j.phytochem.2004.06.008

65. Ahmad N, Katiyar SK, Mukhtar H. Antioxidants in chemoprevention of skin cancer. Curr Probl Dermatol. 2001;29:128-139.

66. Katiyar SK, Agarwal R, Mukhtar H. Inhibition of tumor promotion in SENCAR mouse skin by ethanol extract of Zingiber officinale rhizome. Cancer Res. 1996;56(5):10231030.

67. Surh Y. Molecular mechanisms of chemopreventive effects of selected dietary and medicinal phenolic substances. Mutat Res. 1999;428(1-2):305-327.

68. Manju V, Nalini N. Chemopreventive efficacy of ginger, a naturally occurring anticarcinogen during the initiation, post-initiation stages of 1,2 dimethylhydrazine-induced colon cancer. Clin Chim Acta. 2005;358(1-2):60-67. doi:10.1016/j.cccn.2005.02.018

69. Aktan F, Henness S, Tran VH, Duke CC, Roufogalis BD, Ammit AJ. Gingerol metabolite and a synthetic analogue Capsarol inhibit macrophage NF-kappaB-mediated iNOS gene expression and enzyme activity. Planta Med. 2006;72(8):727-734. doi:10.1055/s-2006-931588

70. Takada Y, Murakami A, Aggarwal BB. Zerumbone abolishes NF-kappaB and IkappaBalpha kinase activation leading to suppression of antiapoptotic and metastatic gene expression, upregulation of apoptosis, and downregulation of invasion. Oncogene. 2005;24(46):6957-6969. doi:10.1038/sj.onc.1208845

71. Kim SO, Chun KS, Kundu JK, Surh YJ. Inhibitory effects of [6]-gingerol on PMA-induced COX-2 expression and activation of NF-kappaB and p38 MAPK in mouse skin. Biofactors. 2004;21(1-4):27-31.

72. Kim SO, Kundu JK, Shin YK, et al. [6]-Gingerol inhibits COX-2 expression by blocking the activation of p38 MAP kinase and NF-kappaB in phorbol ester-stimulated mouse skin. Oncogene. 2005;24(15):2558-2567. doi:10.1038/ sj.onc. 1208446

73. Nonn L, Duong D, Peehl DM. Chemopreventive anti-inflammatory activities of curcumin and other phytochemicals mediated by MAP kinase phosphatase- 5 in prostate cells. Carcinogenesis. 2007;28(6):1188-1196. doi:10.1093/carcin/bgl241

Copyright ( 2017 The Author (s); This is an open-access article distributed under the terms of the Creative Commons Attribution License (http://creativecommons.org/licenses/by/4.0), which permits unrestricted use, distribution, and reproduction in any medium, provided the original work is properly cited. 